\section{RNA methylation by Dnmt2 protects transfer RNAs against stress-induced cleavage}

\author{
Matthias Schaefer, ${ }^{1}$ Tim Pollex, ${ }^{1}$ \\ Katharina Hanna, ${ }^{1}$ Francesca Tuorto, ${ }^{1,2}$ \\ Madeleine Meusburger, ${ }^{1,3}$ Mark Helm, ${ }^{3,4}$ \\ and Frank Lyko ${ }^{1,5}$ \\ ${ }^{1}$ Division of Epigenetics, DKFZ-ZMBH Alliance, German
Cancer Research Center, Heidelberg 69120, Germany; ${ }^{2}$ Institute
of Genetics and Biophysics ABT, CNR, Naples 80131, Italy;
${ }^{3}$ Institute of Pharmacy and Molecular Biotechnology,
Department of Chemistry, University of Heidelberg, Heidelberg
69210, Germany; ${ }^{4}$ Institute of Pharmacy, Johannes
Gutenberg-University of Mainz, Mainz 55128, Germany
}

Dnmt2 proteins are the most conserved members of the DNA methyltransferase enzyme family, but their substrate specificity and biological functions have been a subject of controversy. We show here that, in addition to tRNA ${ }^{\text {Asp-GTC }}$, tRNA ${ }^{\text {Val-AAC }}$ and tRNA ${ }^{\text {Gly-GCC }}$ are also methylated by Dnmt2. Drosophila Dnmt2 mutants showed reduced viability under stress conditions, and Dnmt2 relocalized to stress granules following heat shock. Strikingly, stress-induced cleavage of tRNAs was Dnmt2-dependent, and Dnmt2-mediated methylation protected tRNAs against ribonuclease cleavage. These results uncover a novel biological function of Dnmt2mediated tRNA methylation, and suggest a role for Dnmt 2 enzymes during the biogenesis of tRNA-derived small RNAs.

Supplemental material is available at http://www.genesdev.org.

Received March 25, 2010; revised version accepted June 16, 2010.

The covalent modification of nucleic acids plays an important role in regulating the functions of DNA and RNA. DNA modifications have been analyzed in considerable detail, and the characterization of (cytosine-5) DNA methylation has been crucial for understanding the molecular basis of epigenetic gene regulation (Klose and Bird 2006). (Cytosine-5) methylation has also been documented in various RNA species, including tRNA, but the function of RNA methylation has not been firmly established yet (Motorin et al. 2010).

Dnmt2 proteins were originally assigned to the DNA methyltransferase family, because of their strong sequence conservation of catalytic DNA methyltransferase motifs (Okano et al. 1998; Yoder and Bestor 1998). A recent study has suggested that Dnmt2-mediated DNA methylation is important for transposon silencing in Drosophila (Phalke et al. 2009). However, only a weak

[Keywords: Cytosine methylation; Dnmt2; tRNA; angiogenin] ${ }^{5}$ Corresponding author.

E-MAIL f.lyko@dkfz.de; FAX 49-6221-423802.

Article is online at http://www.genesdev.org/cgi/doi/10.1101/gad.586710. and distributive DNA methylation activity has been reported in various systems (Jeltsch et al. 2006).

The ambiguities associated with the DNA methyltransferase activity of Dnmt2 have also prompted the search for alternative enzyme substrates, and resulted in the discovery of a tRNA methyltransferase activity of Dnmt2 (Goll et al. 2006). Purified recombinant human Dnmt2 methylated RNA preparations from Dnmt2 mutant mice, flies, and plants. Further experiments identified $\mathrm{C} 38$ in the anti-codon loop of tRNA ${ }^{\text {Asp }}$ as the methylation target site of Dnmt2 (Goll et al. 2006). However, the functional relevance of the tRNA methyltransferase activity of Dnmt2 remains to be established. Dnmt2 mutant mice, flies, and plants were reported to be viable and fertile (Goll et al. 2006) under standard laboratory conditions. A distinct Dnmt 2 mutant phenotype, caused by morpholino knockdown experiments, has so far been reported only in zebrafish, leading to lethal differentiation defects in the retina, liver, and brain (Rai et al. 2007). In addition, two studies have indicated increased stress tolerance in Dnmt2-overexpressing flies and amoebas (Lin et al. 2005; Fisher et al. 2006). However, the underlying molecular mechanisms have not been investigated yet.

\section{Results and Discussion}

The Drosophila Dnmt2 locus (chromosome 2, 33C4) gives rise to two transcripts: Dnmt2-RC and Dnmt2RA. The predicted protein products Dnmt2-PC and Dnmt2-PA differ in their $\mathrm{N}$ termini by a peptide stretch of 21 amino acids (Supplemental Fig. S1A), which eliminates the catalytic DNA methyltransferase motif I from the putative Dnmt2-PA protein. Both transcripts were detectable during all stages of development and in adult flies (Fig. 1A), suggesting a general function throughout development.

In order to establish a mutant allele that causes the loss of both transcripts, we generated a deletion in the genomic Dnmt2 locus by mobilizing the P-element EP(2)GE15695, which is located upstream of the Dnmt2 coding sequence (Jurkowski et al. 2008). Since the P-element insertion mapped to the promoter region of both Dnmt2 and the adjacent CG6712 locus, we performed an imprecise excision screen for deletions that allowed the expression of CG6712, but deleted parts of the coding region of Dnmt2. One of the excision alleles generated $\left(\right.$ Dnmt $\left.2^{99}\right)$ contained a proximal deletion of the EP element and fused the remnant of the EP element to the $3^{\prime}$ half of the Dnmt 2 coding region, thereby deleting large parts of the Dnmt2 gene, including motifs I-VII and part of motif VIII (Supplemental Fig. S1B). Quantitative PCR analysis showed that both transcripts generated from the Dnmt2 locus were undetectable in homozygous Dnmt2 ${ }^{99}$ mutants (Supplemental Fig. S1C). Dnmt2 protein could not be detected in embryonic protein extracts from homozygous Dnmt2 ${ }^{99}$ mutants, but was detectable as a $40-\mathrm{kDa}$ polypeptide in wild-type embryos using Dnmt2-specific antibodies (Supplemental Fig. S1D). These results strongly suggested that Dnmt $2^{99}$ represents a null allele suitable for further analysis.

To investigate whether Dnmt2 methylates additional tRNAs, we used RNA bisulfite sequencing, a recently 
A

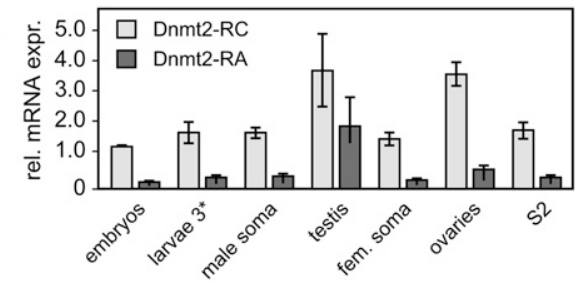

B tRNA ${ }^{\text {Asp-GTC }}(1709 / 1590)$ tRNA ${ }^{\text {Gly-GCC }}(2066 / 2366)$
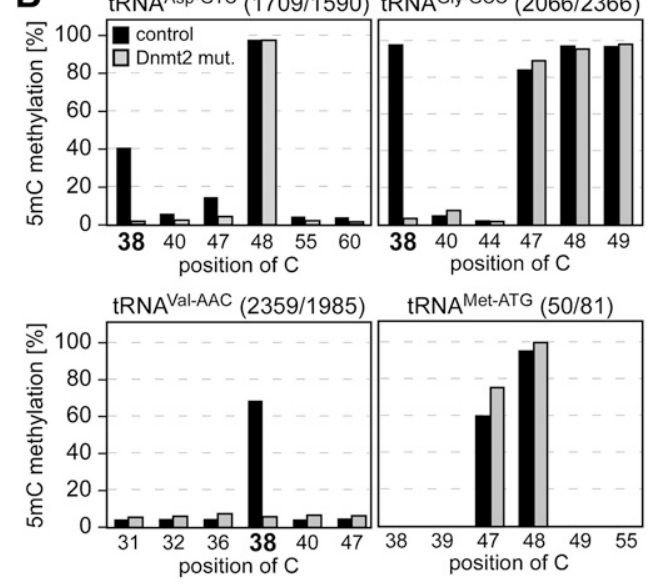

Figure 1. Dnmt2 is a multisubstrate tRNA methyltransferase. $(A)$ Quantitative PCR analysis of Dnmt2 mRNA expression in Drosophila tissues. Expression was normalized to rp49 levels. (B) Identification of novel Dnmt2 substrate tRNAs. Deep bisulfite sequencing analysis of various tRNAs in wild-type (control) and Dnmt2 mutant (Dnmt2 mut.) flies. Numbers of sequence reads are indicated at the top of each panel. Diagrams show fractions of nondeaminated cytosines, thus revealing the pattern of m5C modification in individual tRNAs. Cytosines that were found to be methylated in a Dnmt2-dependent manner are C38 in tRNA ${ }^{\text {Asp-GTC, }}$ tRNA $^{\text {Val-AAC, }}$, and tRNA ${ }^{\mathrm{Gly}-\mathrm{GCC}}$ (highlighted by bold numbers).

established method that allows the direct analysis of RNA methylation patterns in their native sequence context (Schaefer et al. 2009). Obvious candidate substrates were tRNAs that also contain a cytosine residue at position 38, assuming that substrate recognition might be similar to tRNA ${ }^{\text {Asp. }}$. Among these, tRNA ${ }^{\text {Gly }}$ and tRNA ${ }^{\text {Val }}$ warranted particular consideration, because these RNAs have been reported to be methylated at C38 (Garel and Keith 1977; Addison et al. 1982).

Using next-generation sequencing of PCR amplicons derived from bisulfite-treated total RNA, we obtained sequence information for tRNAs from adult Dnmt2 wildtype and $D n m t 2^{99}$ mutant animals. The analysis revealed robust methylation of C38 in tRNA ${ }^{\text {Asp-GTC }}$ from control flies (Dnmt2 $\left.{ }^{\text {rev }}\right)$. In contrast, only background methylation levels were observed in tRNA ${ }^{\text {Asp-GTC }}$ from $D n m t 2^{99}$ mutant flies (Fig. 1B). These results confirmed previous RNA bisulfite sequencing data for tRNA Asp-GTC (Schaefer et al. 2009). Similarly, C38 of tRNA ${ }^{\text {Gly-GCC }}$ and tRNA ${ }^{\mathrm{Val}-\mathrm{AAC}}$ were strongly methylated in control flies, and methylation was close to background levels in Dnmt2 $2^{99}$ mutants (Fig. 1B). Dnmt2-dependent tRNA ${ }^{\text {Val }}$ methylation was also confirmed by site-specific, DNAzymemediated cleavage, and analysis by thin-layer chromatography (Hengesbach et al. 2008), as well as by a biochemical methylation assay using purified recombinant human Dnmt2 (Supplemental Fig. S2). Together, these results demonstrate that the tRNA methyltransferase activity of Dnmt2 is not limited to C38 of tRNA ${ }^{\text {Asp-GTC }}$, and that Dnmt 2 can methylate additional tRNAs both in vitro and in vivo.

Methylation changes in Dnmt2 $2^{99}$ mutants were observed only at C38, and the methylation status of other cytosine residues in the tRNA fragments investigated did not become detectably altered in Dnmt $2^{99}$ mutants (Fig. 1B). A certain level of enzyme specificity was also supported by our findings that other C38-containing tRNAs-including tRNA ${ }^{\text {Met-ATG, }}$ tRNA ${ }^{\text {Glu-CTC }}$, and tRNA $^{\text {His-GTG }}$ - were not detectably methylated in a Dnmt2-dependent manner (Fig. 1B; data not shown).

Dnmt2 ${ }^{99}$ mutant flies were viable and fertile under standard laboratory conditions, as described for other mutant alleles (Goll et al. 2006; Jurkowski et al. 2008). Because a previous study suggested that Dnmt2-overexpressing flies showed increased stress tolerance (Lin et al. 2005), the viability of Dnmt $2^{99}$ animals was analyzed under thermal stress conditions. When flies were raised continuously at $29^{\circ} \mathrm{C}\left(4^{\circ} \mathrm{C}\right.$ above standard temperature), Dnmt $2^{99}$ mutants showed a reduced mean lifespan $(25 \mathrm{~d})$ when compared with Dnmt $2^{\text {rev }}$ controls (30 d) (Fig; 2A). Importantly, transgenic flies carrying a genomic copy of the Dnmt2 locus in the Dnmt299 background (Dnmt $2^{\text {genTG }}$ ) showed a partially or fully restored lifespan (Fig. 2A), indicating that this phenotype is Dnmt2-dependent.

In order to examine a potential function of Dnmt2 in oxidative stress responses, adult male flies were exposed to paraquat, and surviving flies were counted daily. The results showed that the paraquat sensitivity of Dnmt2 ${ }^{99}$
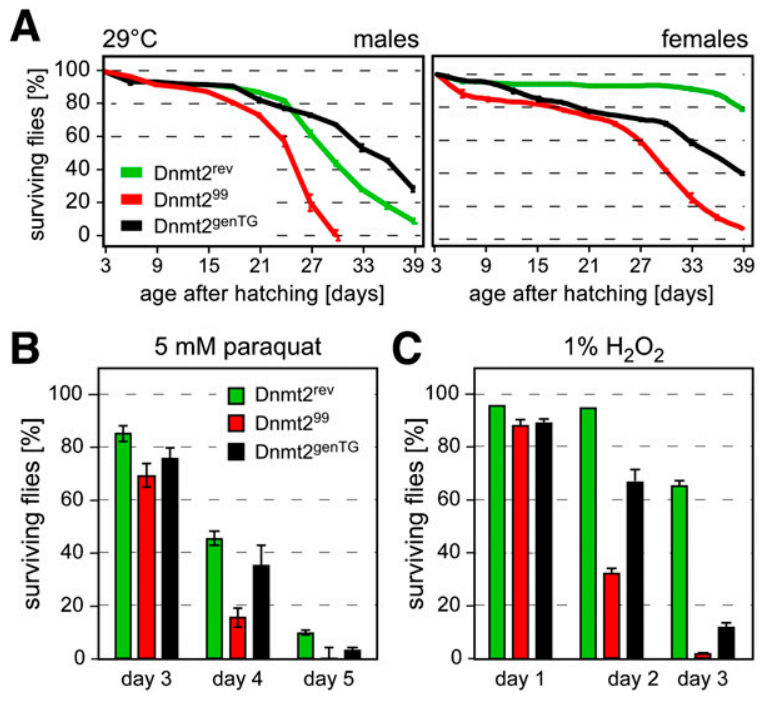

Figure 2. Loss of Dnmt2 causes increased stress sensitivity. $(A)$ Viability plot of Dnmt2 ${ }^{99}$ mutant, control (Dnmt2 ${ }^{\text {rev }}$ ), and transgenic rescue (Dnmt2 ${ }^{\text {genTG}}$ ) flies reared at elevated temperature $\left(29^{\circ} \mathrm{C}\right)$. For each genotype and sex, the survival of 20 flies $(3 \mathrm{~d}$ old $)$ was counted over a period of $39 \mathrm{~d}$. Error bars represent standard deviations from five independent experiments. (B) Dnmt2 mutant flies show elevated sensitivity to paraquat. For each genotype, 20 male or female adult flies were exposed to paraquat, and live flies were counted for $5 \mathrm{~d}$. Error bars represent standard deviations from five independent experiments. $(C)$ Dnmt2 mutant flies show elevated sensitivity to $\mathrm{H}_{2} \mathrm{O}_{2}$. Twenty male or female adult flies were exposed to $1 \% \mathrm{H}_{2} \mathrm{O}_{2}$, and live flies were counted for $3 \mathrm{~d}$. Error bars represent standard deviations from five independent experiments. 
mutant flies was substantially higher than that of control flies (Dnmt2 ${ }^{\text {rev }}$ ) after exposure to $5 \mathrm{mM}$ paraquat (Fig. $2 \mathrm{~B}$ ). Dnmt2 $2^{\text {genTG }}$ showed a robust rescue effect (Fig. 2B), confirming that the increased sensitivity to paraquat is Dnmt2-dependent. Exposing flies to another oxidizing agent, $\mathrm{H}_{2} \mathrm{O}_{2}$, showed that Dnmt2 ${ }^{99}$ mutant flies were also more sensitive to $\mathrm{H}_{2} \mathrm{O}_{2}$ than control flies (Dnmt2 ${ }^{\text {rev }}$ ). The increased sensitivity to $\mathrm{H}_{2} \mathrm{O}_{2}$ was partially rescued when Dnmt2 $2^{\text {genTG }}$ flies were analyzed (Fig. 2C), confirming that the response to $\mathrm{H}_{2} \mathrm{O}_{2}$ is mediated by Dnmt2. The appearance of Dnmt2 mutant phenotypes under stress conditions implies that Dnmt2 is associated with Drosophila stress response pathways.

Having identified a role of Dnmt2 in stress responses, we analyzed the association of the protein with cellular stress compartments. To analyze the subcellular localization of Dnmt2 under stress conditions, we used flies expressing EGFP-tagged Dnmt2 from a genomic construct in the Dnmt2 ${ }^{99}$ background (Dnmt2 $2^{\text {genTG-EGFP). }}$ Activity of the tagged Dnmt2 construct was confirmed by bisulfite sequencing of tRNA from adult males, which showed that C38 methylation of tRNA ${ }^{\text {Asp-GTC }}$ and tRNA ${ }^{\text {Gly-GCC }}$ was restored to wild-type levels (Supplemental Fig. S3). Methylation was not rescued for tRNA ${ }^{\text {Val-AAC }}$ (Supplemental Fig. S3), which indicates that the transgenic construct does not completely restore Dnmt2 expression or functionality in all tissues or developmental stages. These findings are consistent with the incomplete rescue of stress phenotypes observed with tagged genomic constructs (see Fig. 2). Ovaries from Dnmt $2^{\text {genTG-EGFP }}$ flies showed a homogeneous, mostly cytoplasmic distribution of Dnmt2-EGFP, which aggregated into discernable granular loci after heat shock. This increase in granular Dnmt2-EGFP signal was observed in both live and fixed ovarian tissue (Supplemental Fig. S4), thus excluding fixation artifacts. Similar results were also obtained with Drosophila S2 cells stably expressing Dnmt2-EGFP, and pronounced Dnmt2-EGFP-positive granules became visible after heat shock (Fig. 3A).

To confirm the association of Dnmt2 with stress-related subcellular compartments, we costained heatshocked S2 cells for Dnmt2-EGFP and fragile X mental retardation 1 (FMR1), a ubiquitious RNA-binding protein that relocalizes to stress granules in Drosophila (Farny et al. 2009). The results showed that part of the Dnmt2EGFP signal clearly colocalized with FMR1 loci (Fig. 3A). A distinct colocalization between Dnmt2-EGFP and FMR1 after heat shock was also observed in ovaries (Fig. 3B). Staining of Dnmt2 $2^{\text {genTG-EGFP }}$ ovaries with an antibody to ME31B, a Drosophila RNA processing body component in the germline (Lin et al. 2006), also showed processing body signals after heat shock with strong colocalization of Dnmt2 and ME31B (Fig. 3C). Together, these data illustrate the ability of Dnmt2 to localize to stress granules and RNA processing bodies following heat shock, and thus further illustrate the association between the subcellular localization of Dnmt2 and stress response pathways.

Stress granules and processing bodies contain high numbers of RNA molecules (Anderson and Kedersha 2009), and heat-shock stress responses have been linked to changes in RNA methylation in bacteria (Bugl et al. 2000). Interestingly, tRNA cleavage in the anticodon loop has been identified recently as a molecular mechanism associated with eukaryotic stress responses

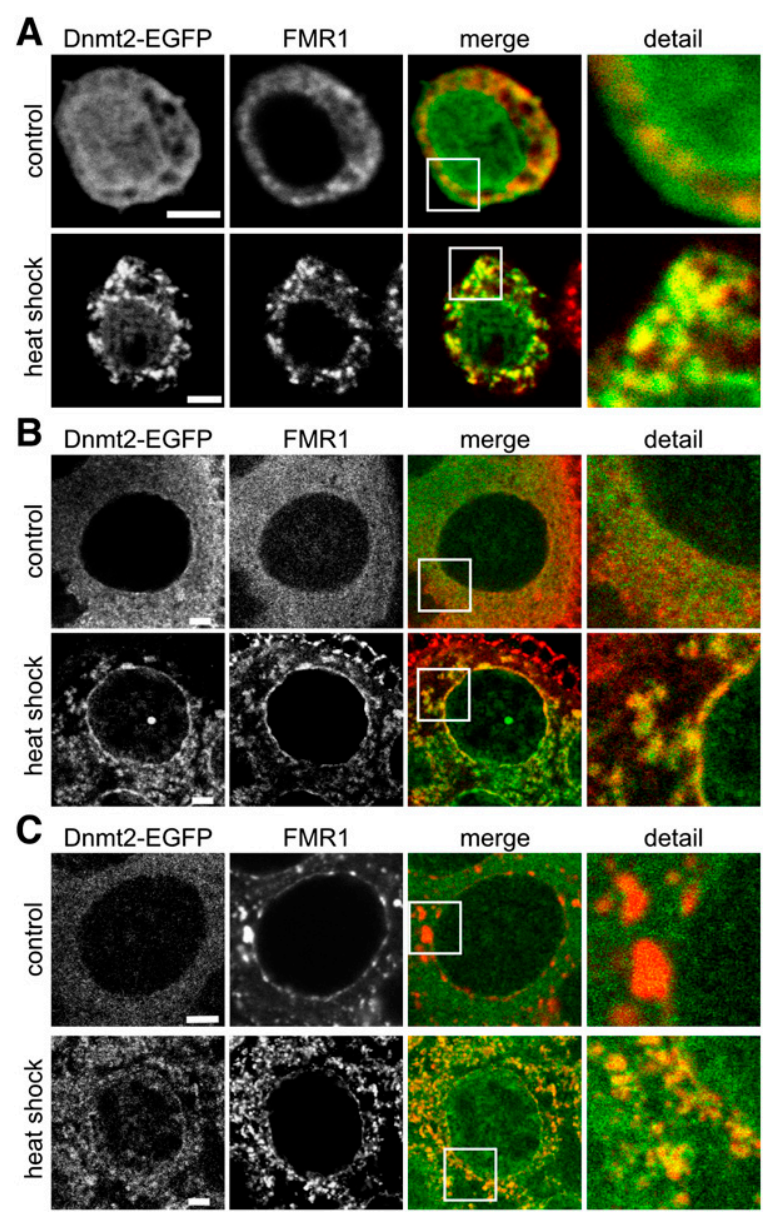

Figure 3. Dnmt2 is associated with stress compartments. $(A)$ Immunofluorescence analysis of FMR1 in S2 cells expressing Dnmt2-EGFP. FMR1 localizes to the cytoplasm, whereas Dnmt2EGFP is localized ubiquitiously to the cytoplasm and nucleus in control cells. Upon heat shock $\left(1 \mathrm{~h}\right.$ at $\left.40^{\circ} \mathrm{C}\right)$, FMR 1 concentrates in large cytoplasmic granules where the signal colocalizes with granular Dnmt2-EGFP. (B) Similar observations were made in ovaries after heat shock. (C) Immunofluorescence analysis of the P-bodyassociated protein ME31B on fixed Dnmt2-EGFP ovaries. After heat shock, the number of ME31B foci increased, and colocalization with Dnmt2-EGFP structures could be observed. Bars: $A, 10 \mu \mathrm{M} ; B, C$, $1 \mu \mathrm{M}$.

(Thompson et al. 2008; Yamasaki et al. 2009). We therefore established whether tRNA cleavage under thermal and oxidative stress conditions is conserved for Dnmt2 substrates and in Drosophila. Using Drosophila S2 cells, we investigated the cleavage of tRNA ${ }^{\text {Gly-GCC }}$ as a representative Dnmt2 substrate. Northern analysis showed the rapid appearance of tRNA Gly-GCC fragments following heat shock (Fig. 4A), and also indicated tRNA Gly-GCC cleavage following oxidative stress by $\mathrm{H}_{2} \mathrm{O}_{2}$ and arsenite, respectively (Fig. 4B). A slight, heat-shock-dependent increase of tRNA Gly-GCC fragments was also observed by Northern analysis of RNA prepared from ovaries (Fig. 4C). Notably, this effect became much more pronounced when tRNA ${ }^{\text {Gly-GCC }}$ cleavage was analyzed in ovaries from aged Dnmt2 ${ }^{99}$ mutant females (Fig. 4C), thus suggesting a role of Dnmt2 in the regulation of tRNA cleavage. To confirm these findings, we used transgenic S2 
A
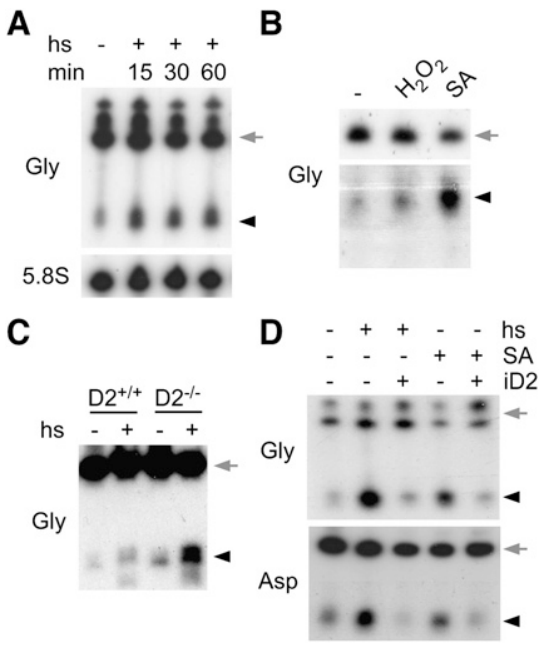

Figure 4. Stress-induced cleavage of Dnmt2 substrate tRNAs. $(A)$ Northern analysis of tRNA ${ }^{\text {Gly-GCC }}$ cleavage in S2 cells that were heat-shocked $\left(1 \mathrm{~h}\right.$ at $\left.40^{\circ} \mathrm{C}\right)$ for the times (in minutes) indicated. $5.8 \mathrm{~S}$ rRNA was used as a loading control. $(B)$ Cleavage of tRNA ${ }^{\mathrm{Gly}-\mathrm{GCC}}$ in S2 cells that were treated with $\mathrm{H}_{2} \mathrm{O}_{2}\left(1 \mathrm{mM} \mathrm{H} \mathrm{H}_{2} \mathrm{O}_{2}, 60 \mathrm{~min}\right)$ or sodium arsenite $(0.5 \mathrm{mM} \mathrm{SA}, 90 \mathrm{~min})$. (C) Cleavage of tRNA Gly-GCC in wild-type $\left(\mathrm{D}^{+/+}\right)$or Dnmt 2 mutant $\left(\mathrm{D} 2^{-l-}\right)$ ovaries (resected 35 $\mathrm{d}$ after hatching) that were heat-shocked $(+)$ in medium at $40^{\circ} \mathrm{C}$. Controls $(-)$ show results from parallel experiments with ovary incubation at $25^{\circ} \mathrm{C}$. $(D)$ Northern analysis of tRNA ${ }^{\mathrm{Gly}-\mathrm{GCC}}$ and tRNA $^{\text {Asp-GTC }}$ cleavage in S2 cells that allow inducible overexpression of Dnmt2 (iD2). Full-length tRNAs are marked by gray arrows, and tRNA fragments are marked by black arrowheads.

cells that allow inducible overexpression of Dnmt2. When these cells were subjected to heat shock or oxidative stress, Northern blot analysis showed the stressdependent appearance of tRNA ${ }^{\text {Gly-GCC }}$ fragments (Fig. 4D). Ectopic expression of Dnmt2 substantially decreased the amount of detectable cleavage products (Fig. 4D). Essentially similar results were also obtained when analyzing tRNA ${ }^{\text {Asp-GTC }}$ (Fig. 4D). Together, these findings indicate that either Dnmt2 binding to tRNAs or ectopic Dnmt2-mediated tRNA methylation protected tRNA ${ }^{\text {Gly-GCC }}$ and tRNA ${ }^{\text {Asp-GTC }}$ molecules from cleavage.

The RNase A-like ribonuclease angiogenin has been shown recently to mediate stress-induced tRNA cleavage in human cells (Yamasaki et al. 2009). Since the endonuclease targeting the anti-codon loop of Drosophila tRNAs has not been identified yet, we treated Drosophila S2 cells with recombinant human angiogenin and analyzed cleavage of tRNA ${ }^{\text {Asp-GTC }}$ and tRNA Gly-GCC by Northern blot analysis. The results clearly showed that exogenous angiogenin induces the generation of small tRNA fragments (Fig. 5A). Importantly, Dnmt2 overexpression protected Dnmt2 substrate tRNAs from angiogenin cleavage, while tRNA ${ }^{\text {Met-ATG }}$, which is not a substrate of Dnmt2, remained unaffected by Dnmt2 overexpression (Fig. 5A). These experiments indicated that Dnmt2 functions to protect against angiogenin-mediated tRNA cleavage.

To test whether Dnmt2-mediated tRNA methylation at C38 inhibits angiogenin-catalyzed tRNA cleavage, we purified tRNAs from wild-type and Dnmt2 mutant embryos, and incubated these RNAs with recombinant angiogenin in a biochemical assay. Northern blot analysis showed very low levels of angiogenin cleavage of
tRNA $^{\text {Asp-GTC }}$ tRNA ${ }^{\text {Gly-GCC }}$, and tRNA ${ }^{\text {Val-AAC }}$ when the tRNAs were isolated from wild-type embryos (Fig. 5B). In contrast, all three Dnmt2 substrates were cleaved efficiently when the tRNAs were purified from Dnmt2 mutant embryos (Fig. 5B). The cleavage kinetics on tRNA $^{\text {Met-ATG }}$ was not affected by the genotype of the RNA preparation (Fig. 5B), which confirmed that C38 methylation functions to protect Dnmt2 substrate tRNAs from endonucleolytic cleavage. While small RNA sequencing studies have indicated cleavage sites in the vicinity of the Dnmt2 target nucleotide C38 (Kawaji et al. 2008; Fu et al. 2009), angiogenin is also known to be a ribonuclease with comparably low specificity (Rybak and Vallee 1988). We therefore determined the cleavage sites by sequencing of $5^{\prime}$-tRNA fragments from tRNA ${ }^{\text {Asp-GTC }}$, tRNA Gly-GCC, and tRNA ${ }^{\text {Val-AAC }}$. The results showed cleavage at various positions in the anticodon stem-loop (Supplemental Fig. S5), suggesting an effect of C38 methylation on the structure and endonuclease accessibility of this tRNA region.

Because of the remarkable evolutionary conservation of Dnmt2, we sought to confirm the function of Dnmt2 in endonuclease cleavage protection in a different model

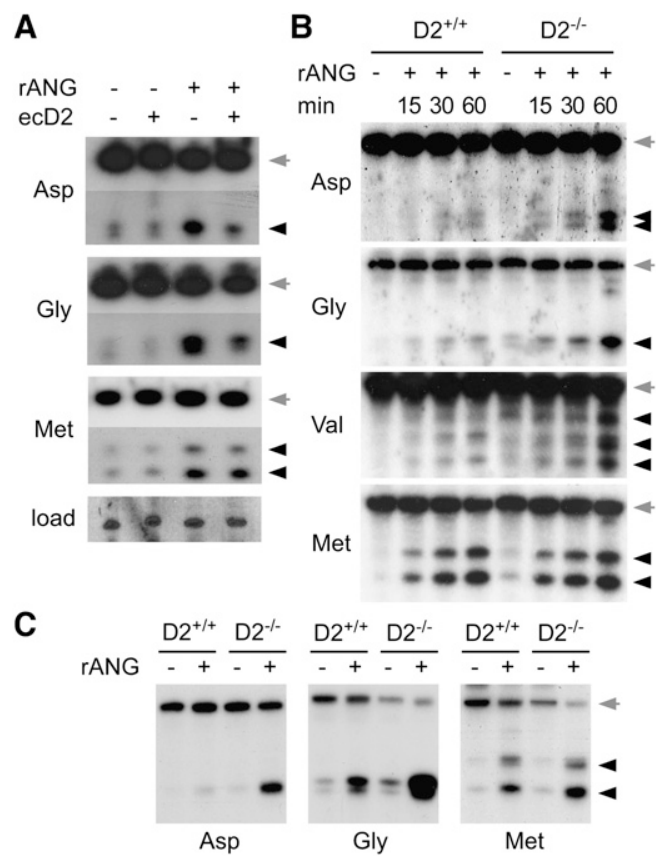

Figure 5. Dnmt2-mediated tRNA methylation inhibits endonucleolytic cleavage by angiogenin. (A) Dnmt2 overexpression (ecD2) inhibits angiogenin-induced tRNA cleavage. tRNA cleavage was induced in S2 cells by the addition of recombinant angiogenin (rANG) to the medium $(1 \mu \mathrm{g} / \mathrm{mL})$, and was analyzed by Northern blotting. Full-length tRNAs (gray arrows) and cleavage products (black arrowheads) are shown from the same original blot. (B) Dnmt2 substrate tRNAs isolated from wild-type embryos $\left(\mathrm{D}^{+/+}\right)$are protected against angiogenin cleavage in vitro. No protection effect was observed with Dnmt2 substrate tRNAs isolated from Dnmt2 mutant embryos $\left(\mathrm{D}^{-1-}\right)$, or with tRNA ${ }^{\text {Met-ATG }}$, which is not a Dnmt2 substrate. $(C)$ Dnmt2-mediated protection against angiogenin cleavage is conserved in mice. tRNA was purified from wild-type $\left(\mathrm{D} 2^{+/+}\right)$ or Dnmt2 mutant $\left(\mathrm{D} 2^{-1-}\right) \mathrm{MEFs}$, incubated with recombinant angiogenin (1 $\mu \mathrm{M}, 60 \mathrm{~min})$, and analyzed by Northern blotting. Full-length tRNAs are marked by gray arrows, and tRNA fragments are marked by black arrowheads. 
system. To this end, we derived embryonic fibroblasts from wild-type and Dnmt2 homozygous mutant mice (Goll et al. 2006). tRNAs were isolated from both cell lines, and Dnmt2-dependent tRNA ${ }^{\text {Asp-GTC }}$ methylation at C38 was confirmed by RNA bisulfite sequencing (Supplemental Fig. S6). Purified tRNAs from wild-type and Dnmt2 mutant mouse embryonic fibroblasts (MEFs) were incubated with recombinant angiogenin, and tRNA cleavage of tRNA ${ }^{\text {Asp-GTC }}$, tRNA Gly-GCC, and tRNA ${ }^{\text {Met-ATG }}$ was analyzed by Northern blot. The results showed a clear protection against angiogenin cleavage for the Dnmt2 substrates tRNA ${ }^{\text {Asp-GTC }}$ and tRNA ${ }^{\text {Gly-GCC }}$ if derived from Dnmt2 mutant MEFs, but not for tRNA ${ }^{\text {Met-ATG }}$ (Fig. 5C). These data provide important confirmation for a role of Dnmt2-mediated tRNA methylation in protection from endonucleolytic cleavage.

The lack of phenotypic and molecular data has been a major obstacle in defining the biological function of Dnmt2. The distributive Dnmt2-mediated DNA methylation that was reported in several studies (Jeltsch et al. 2006) has been difficult to interpret as biologically relevant. Similarly, the methylation of a single cytosine residue in a single tRNA made it difficult to envisage a fundamental biological role for Dnmt2 enzymes. However, the initial assumption that Dnmt2 activity is restricted to tRNA ${ }^{\text {Asp }}$ was based largely on a low-resolution analysis of cellular RNAs (Goll et al. 2006). The recent development of RNA bisulfite sequencing (Schaefer et al. 2009), and the use of methods for the purification and site-specific methylation analysis of defined tRNAs (Hengesbach et al. 2008) allowed us to identify additional tRNAs that were methylated by Dnmt2 in Drosophila, thus providing evidence for multisubstrate methyltransferase activity of Dnmt2. Multisubstrate specificity has been described for other RNA modification enzymes, including pseudouridine synthase 1 (Behm-Ansmant et al. 2006), and, significantly, TRM4, the only other characterized cytosine-5 tRNA methyltransferase (Motorin and Grosjean 1999). Considering that TRM4 methylates minisubstrates as small as 40 nucleotides, it remains a possibility that other unidentified substrate RNAs (e.g., small regulatory RNAs) might be methylated by RNA methyltransferases such as Dnmt2. Furthermore, since we were unable to reproduce Dnmt2-dependent DNA methylation of Invader4 transposons in Drosophila, it remains possible that the reported role of Dnmt2 in transposon silencing is mediated by the RNA methyltransferase activity of the enzyme ( $M$ Schaefer and F Lyko, in prep.).

It has been established recently that ribonucleases play an important role in the stress-induced cleavage of tRNAs (Yamasaki et al. 2009), a mechanism that promotes the assembly of stress granules (Emara et al. 2010). Our results suggest that endonucleolytic cleavage of Dnmt2 substrate tRNAs can be inhibited by the methylation mark at C38. While it is known that the $\mathrm{mcm}^{5} \mathrm{~s}^{2}$ modification of U34 can promote the cleavage of certain yeast tRNAs by the Kluveromyces lactics $\gamma$-toxin endonuclease (Lu et al. 2008), our findings represent the first example for the inhibition of ribonucleases by cytosine- 5 RNA methylation.

Defined tRNA fragments have been identified through small RNA cloning approaches (Kawaji et al. 2008; Cole et al. 2009; Haussecker et al. 2010), suggesting a physiological role for tRNA fragments. Interestingly, tRNA fragments can be processed to smaller RNAs by the Dicer RNase, indicating a potential interaction of tRNA-derived sequences and canonical small RNA processing pathways (Cole et al. 2009). Indeed, a recent study provided evidence that tRNA-derived small RNAs act to down-regulate target mRNAs, and affect different RNA silencing pathways by associating with effector core components (Haussecker et al. 2010). This suggests that altered tRNA cleavage (e.g., under stress conditions) could have phenotypic consequences.

\section{Materials and methods}

\section{tRNA bisulfite sequencing}

Total RNA isolation and bisulfite conversions were carried out as described before (Schaefer et al. 2009). Primer sequences are indicated in Supplemental Table S1. Amplicons were analyzed on a GS FLX 454 sequencer (Roche). Bioinformatic analysis was performed using a mapping script for individual bar-coded reads developed in Biopython.

\section{Phenotype analysis}

For survival assays, 20 flies were maintained on standard medium at $25^{\circ} \mathrm{C}$ or $29^{\circ} \mathrm{C}, 60 \%$ humidity, under a 12 -h light-dark cycle, and were transferred to new medium every $3 \mathrm{~d}$. Mortality was scored at transfer times. Twenty flies were tested for each genotype in five biological replicates. Paraquat (methyl viologen) and $\mathrm{H}_{2} \mathrm{O}_{2}$ toxicity assays were performed on 2 -d-old animals placed in vials (20 per vial) with food media made of $1.3 \%$ agar containing $1 \%$ sucrose and $5 \mathrm{mM}$ paraquat (Sigma) or $1 \%$ $\mathrm{H}_{2} \mathrm{O}_{2}$, respectively. Surviving animals were scored daily. Twenty flies were tested for each genotype in five biological replicates.

\section{tRNA cleavage assays}

S2 cells containing pRmHA3-Dnmt2-Flag constructs were induced with $0.7 \mathrm{mM} \mathrm{CuSO}_{4}$, chased with medium without copper for $5 \mathrm{~h}$, and treated with $1 \mu \mathrm{g} / \mathrm{mL}$ angiogenin (R\&D Systems) for $1 \mathrm{~h}$ at $25^{\circ} \mathrm{C}$. RNA was extracted and separated on $15 \%$ urea-PAGE, transferred to Nytran SuperCharge membranes (Schleicher and Schuell Bioscience), and hybridized overnight at $47^{\circ} \mathrm{C}$ with ${ }^{32} \mathrm{P}$-end-labeled oligonucleotides /detecting both $5^{\prime}$ and $3^{\prime}$ ends of tRNAs) in hybridization solution $(5 \times$ SSC, $20 \mathrm{mM}$ $\mathrm{Na}_{2} \mathrm{HPO}_{4}$ at $\mathrm{pH} 7.4,7 \%$ SDS, $1 \times$ Denhardt's). After washing with $3 \times \mathrm{SSC} /$ $5 \% \operatorname{SDS}\left(15 \mathrm{~min}\right.$ at $\left.47^{\circ} \mathrm{C}\right)$ and with $1 \times \mathrm{SSC} / 1 \% \mathrm{SDS}(15 \mathrm{~min}$ at room temperature), membranes were exposed to film at $-80^{\circ} \mathrm{C}$. For in vitro cleavage assays, $1.3 \mu \mathrm{g}$ of urea-PAGE-purified tRNA was heated in water for $5 \mathrm{~min}$ at $80^{\circ} \mathrm{C}$, followed by addition of cleavage buffer $(30 \mathrm{mM}$ Hepes at $\mathrm{pH} 6.8,30 \mathrm{mM} \mathrm{NaCl}, 10 \mathrm{mM} \mathrm{MgCl} \mathrm{m}_{2}$ ). tRNA was allowed to renature for $15 \mathrm{~min}$ to room temperature. BSA (to $0.001 \%$ ) and angiogenin (to $1 \mu \mathrm{M}$ ) were added, and the reaction was incubated for the indicated times at $37^{\circ} \mathrm{C}$, followed by separation on $15 \%$ urea-PAGE, blotting, and hybridization as described above.

\section{MEFS}

MEFs were derived from day 13.5 isogenic Dnmt $2^{-/-}$(Goll et al. 2006) and wild-type embryos. Single embryos were genotyped, dispersed, and trypsinized in a 10-cm-diameter dish. Cells were maintained in DMEM supplemented with $10 \%$ fetal bovine serum and a commercial cocktail of antibiotics (Invitrogen), and were passaged serially according to the 3T3 protocol (Todaro and Green 1963) until spontaneus immortalization.

See the Supplemental Material for additional details.

\section{Acknowledgments}

We thank Akira Nakamura (RIKEN Center for Developmental Biology, Japan) for providing the anti-ME31B antibody. This work was supported by grants from the Deutsche Forschungsgemeinschaft to M.H. (HE 3397/6-1), M.S., and F.L. (Priority Programme Epigenetics, FOR1082). 


\section{References}

Addison WR, Gillam IC, Tener GM. 1982. The nucleotide sequence of tRNA4Val of Drosophila melanogaster. Chloroacetaldehyde modification as an aid to RNA sequencing. I Biol Chem 257: 674-677.

Anderson P, Kedersha N. 2009. RNA granules: Post-transcriptional and epigenetic modulators of gene expression. Nat Rev Mol Cell Biol 10: 430-436.

Behm-Ansmant I, Massenet S, Immel F, Patton JR, Motorin Y, Branlant C. 2006. A previously unidentified activity of yeast and mouse RNA: pseudouridine synthases 1 (Puslp) on tRNAs. RNA 12: 1583-1593.

Bugl H, Fauman EB, Staker BL, Zheng F, Kushner SR, Saper MA, Bardwell JC, Jakob U. 2000. RNA methylation under heat shock control. Mol Cell 6: 349-360.

Cole C, Sobala A, Lu C, Thatcher SR, Bowman A, Brown JW, Green PJ, Barton GJ, Hutvagner G. 2009. Filtering of deep sequencing data reveals the existence of abundant Dicer-dependent small RNAs derived from tRNAs. RNA 15: 2147-2160.

Emara MM, Ivanov P, Hickman T, Dawra N, Tisdale S, Kedersha N, Hu GF, Anderson P. 2010. Angiogenin-induced tiRNAs promote stressinduced stress granule assembly. I Biol Chem 285: 10959-10968.

Farny NG, Kedersha NL, Silver PA. 2009. Metazoan stress granule assembly is mediated by P-eIF $2 \alpha$-dependent and -independent mechanisms. RNA 15: 1814-1821.

Fisher O, Siman-Tov R, Ankri S. 2006. Pleiotropic phenotype in Entamoeba histolytica overexpressing DNA methyltransferase (Ehmeth). Mol Biochem Parasitol 147: 48-54.

Fu H, Feng J, Liu Q, Sun F, Tie Y, Zhu J, Xing R, Sun Z, Zheng X. 2009. Stress induces tRNA cleavage by angiogenin in mammalian cells. FEBS Lett 583: 437-442.

Garel JP, Keith G. 1977. Nucleotide sequence of Bombyx mori L. tRNA1Gly. Nature 269: 350-352.

Goll MG, Kirpekar F, Maggert KA, Yoder JA, Hsieh CL, Zhang X, Golic KG, Jacobsen SE, Bestor TH. 2006. Methylation of tRNAAsp by the DNA methyltransferase homolog Dnmt2. Science 311: 395-398.

Haussecker D, Huang Y, Lau A, Parameswaran P, Fire AZ, Kay MA. 2010. Human tRNA-derived small RNAs in the global regulation of RNA silencing. RNA 16: 673-695.

Hengesbach M, Meusburger M, Lyko F, Helm M. 2008. Use of DNAzymes for site-specific analysis of ribonucleotide modifications. RNA 14: 180-187.

Jeltsch A, Nellen W, Lyko F. 2006. Two substrates are better than one: Dual specificities for Dnmt2 methyltransferases. Trends Biochem Sci 31: 306-308.

Jurkowski TP, Meusburger M, Phalke S, Helm M, Nellen W, Reuter G, Jeltsch A. 2008. Human DNMT2 methylates tRNAAsp molecules using a DNA methyltransferase-like catalytic mechanism. RNA 14: $1663-1670$.

Kawaji H, Nakamura M, Takahashi Y, Sandelin A, Katayama S, Fukuda S, Daub CO, Kai C, Kawai J, Yasuda J, et al. 2008. Hidden layers of human small RNAs. BMC Genomics 9: 157. doi: 10.1186/1471-21649-157.

Klose RJ, Bird AP. 2006. Genomic DNA methylation: The mark and its mediators. Trends Biochem Sci 31: 89-97.

Lin MJ, Tang LY, Reddy MN, Shen CK. 2005. DNA methyltransferase gene dDnmt2 and longevity of Drosophila. J Biol Chem 280: 861-864.

Lin MD, Fan SJ, Hsu WS, Chou TB. 2006. Drosophila decapping protein 1, $\mathrm{dDcp} 1$, is a component of the oskar mRNP complex and directs its posterior localization in the oocyte. Dev Cell 10: 601-613.

Lu J, Esberg A, Huang B, Bystrom AS. 2008. Kluyveromyces lactis $\gamma$-toxin, a ribonuclease that recognizes the anticodon stem loop of tRNA. Nucleic Acids Res 36: 1072-1080.

Motorin Y, Grosjean H. 1999. Multisite-specific tRNA:m5C-methyltransferase (Trm4) in yeast Saccharomyces cerevisiae: Identification of the gene and substrate specificity of the enzyme. RNA 5: 1105-1118.

Motorin Y, Lyko F, Helm M. 2010. 5-methylcytosine in RNA: Detection, enzymatic formation and biological functions. Nucleic Acids Res 38: $1415-1430$

Okano M, Xie S, Li E. 1998. Cloning and characterization of a family of novel mammalian DNA (cytosine-5) methyltransferases. Nat Genet 19: $219-220$.

Phalke S, Nickel O, Walluscheck D, Hortig F, Onorati MC, Reuter G. 2009. Retrotransposon silencing and telomere integrity in somatic cells of Drosophila depends on the cytosine 5 methyltransferase DNMT2. Nat Genet 41: 696-702.

Rai K, Chidester S, Zavala CV, Manos EJ, James SR, Karpf AR, Jones DA Cairns BR. 2007. Dnmt2 functions in the cytoplasm to promote liver, brain, and retina development in zebrafish. Genes Dev 21: 261-266.

Rybak SM, Vallee BL. 1988. Base cleavage specificity of angiogenin with Saccharomyces cerevisiae and Escherichia coli 5S RNAs. Biochemistry 27: 2288-2294.

Schaefer M, Pollex T, Hanna K, Lyko F. 2009. RNA cytosine methylation analysis by bisulfite sequencing. Nucleic Acids Res 37: e12. doi: $10.1093 / \mathrm{nar} / \mathrm{gkn} 954$.

Thompson DM, Lu C, Green PJ, Parker R. 2008. tRNA cleavage is a conserved response to oxidative stress in eukaryotes. RNA 14: 2095-2103.

Todaro GJ, Green H. 1963. Quantitative studies of the growth of mouse embryo cells in culture and their development into established lines. J Cell Biol 17: 299-313.

Yamasaki S, Ivanov P, Hu GF, Anderson P. 2009. Angiogenin cleaves tRNA and promotes stress-induced translational repression. J Cell Biol 185: 35-42.

Yoder JA, Bestor TH. 1998. A candidate mammalian DNA methyltransferase related to pmtlp of fission yeast. Hum Mol Genet 7: 279-284. 


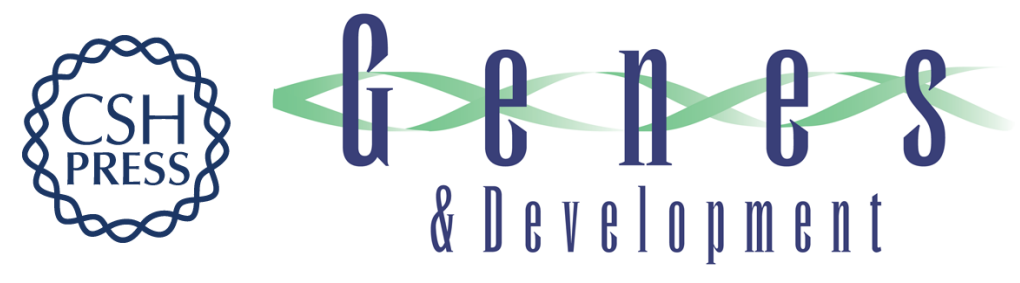

\section{RNA methylation by Dnmt2 protects transfer RNAs against stress-induced cleavage}

Matthias Schaefer, Tim Pollex, Katharina Hanna, et al.

Genes Dev. 2010, 24:

Access the most recent version at doi:10.1101/gad.586710

Supplemental http://genesdev.cshlp.org/content/suppl/2010/07/26/24.15.1590.DC1
Material

References This article cites 31 articles, 15 of which can be accessed free at:

http://genesdev.cshlp.org/content/24/15/1590.full.html\#ref-list-1

License

Email Alerting

Receive free email alerts when new articles cite this article - sign up in the box at the top

Service

right corner of the article or click here.

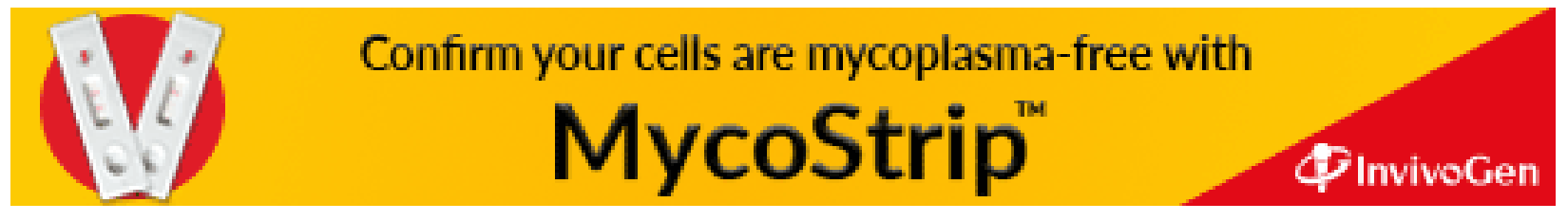

